\title{
Evaluation system for arrhythmogenic potential of drugs using human-induced pluripotent stem cell-derived cardiomyocytes and gene expression analysis
}

\author{
Arisa Higa, Hirotaka Hoshi, Yuka Yanagisawa, Emi Ito, Gaku Morisawa, Jun-ichi Imai, \\ Shinya Watanabe and Motoki Takagi \\ Medical-Industrial Translational Research Center, Fukushima Medical University, \\ 1 Hikariga-oka, Fukushima, Fukushima 960-1295, Japan
}

(Received August 15, 2017; Accepted September 22, 2017)

\begin{abstract}
In recent years, human-induced pluripotent stem cell-derived cardiomyocytes (hiPS$\mathrm{CMs}$ ) have been widely used to develop evaluation systems for drug cardiotoxicity, including the arrhythmia caused by QT prolongation. To accurately assess the arrhythmogenic potential of drugs, associated with QT prolongation, we developed an evaluation system using hiPS-CMs and gene expression analysis. hiPS-CMs were treated with 8 arrhythmogenic and 17 non-arrhythmogenic drugs at several concentrations for $24 \mathrm{hr}$ to comprehensively analyze gene expression. The results showed that 19 genes were upregulated in the arrhythmogenic drug-treated cells compared with their expression levels in the nontreated and non-arrhythmogenic drug-treated cells. The arrhythmogenic risks of the drugs were evaluated by scoring gene expression levels. The results indicated that arrhythmogenic risks could be inferred when cells were treated at a concentration 100 times higher than the maximum blood concentration of the drug. Thus, we succeeded in developing a system for evaluation of the arrhythmogenic potential of drugs using gene expression analysis.
\end{abstract}

Key words: Arrhythmia, Arrhythmogenesis, QT prolongation, Human-induced pluripotent stem cell-derived cardiomyocytes, Gene expression analysis

\section{INTRODUCTION}

Unexpected cardiotoxicity is a major concern in drug development and a major cause of drug withdrawal from the market. From 1990 to 2001, eight drugs were withdrawn from the market because they induced QT interval prolongation, which is the major cause of ventricular tachycardia, such as Torsades de pointes (TdP), associated with distortions in transmembrane ion flux, polymorphic ventricular tachyarrhythmia, seizures, and sudden death (Fermini and Fossa, 2003). Thus, several in vitro and in vivo assays have been established to evaluate druginduced QT prolongation for preclinical cardiac safety assessment of drugs. However, the assays may produce false-positive or false-negative results, and species differences in drug responses between humans and animals are also a problem. Moreover, when animal experiments are involved, the principles of 3Rs, replacement, refinement, and reduction, should be integrated (Fermini and Fossa,
2003; Omata et al., 2005).

To overcome these problems, human-induced stem cell-derived cardiomyocytes (hiPS-CMs) have been recently introduced as a tool for preclinical cardiac safety assessment, including the evaluation of arrhythmia with QT prolongation induced by drugs (Šarić et al., 2014). Assessment of the arrhythmogenic drug potential is based on recording electrical activity of the cardiomyocytes, including extracellular recording with sharp or patch electrodes (Honda et al., 2011), extracellular recording with multi-electrode arrays (MEA) (Asakura et al., 2015; Dick et al., 2010; Guo et al., 2011), optical imaging with voltage-sensitive dyes (Hayakawa et al., 2014; LopezIzquierdo et al., 2014), and continuous monitoring of the impedance readout with microelectronic plates (Guo et al., 2011, 2013; Higa et al., 2016; Nguemo et al., 2012). These assays detect changes in electrical activity of cardiomyocytes upon drug treatment for a short period (several minutes to several hours). The Consortium for Safety

Correspondence: Motoki Takagi (E-mail: m-takagi@fmu.ac.jp) 
Assessment using Human iPS Cells (CSAHi) initiated an effort to establish standard protocols by MEA systems for risk assessment of arrhythmia and QT prolongation using various reference drugs (Ando et al., 2017; Asakura et al., 2015; Nozaki et al., 2016, 2017; Yamamoto et al., 2016). In those experimental processes, Nozaki et al. (2017) investigated gene expression profiles using hiPS-CMs that were cultured in three different facilities to assess the equivalency of the data among laboratories; there was no difference among the gene expression profiles in the three facilities. However, gene expression profiles obtained from arrhythmogenic drug-treated hiPS-CMs have not yet been reported. In this study, we developed a new system to evaluate arrhythmogenic risks associated with drug-induced QT prolongation, using gene expression analysis and a prolonged drug treatment period $(24 \mathrm{hr})$, which is a distinctly different method from the existing technique.

\section{MATERIALS AND METHODS}

\section{Drugs and reagents}

Ambrisentan, amlodipine, bisoprolol, candesartan, linagliptin, naftopidil, prasugrel, and sumatriptan were purchased from Selleck Chemicals (Houston, TX, USA). Clonidine, glyburide, lisinopril, nicorandil, and propafenone were obtained from Wako (Tokyo, Japan). Efonidipine, mibefradil, terfenadine, and terodiline were provided by Sigma-Aldrich (St. Louis, MO, USA). Aliskiren and warfarin were from LKT Laboratories (St. Paul, MN, USA); astemizole and bepridil were from Tocris Bioscience (Bristol, UK); amiodarone and atorvastatin were from Toronto Research Chemicals (Toronto, Canada); cisapride was from Abcam (Cambridge, UK); and ketotifen was from Tokyo Chemical Industry (Tokyo, Japan). All compounds were dissolved in a mixture of dimethyl sulfoxide (DMSO) and methanol (7:3), and were stored at $-80^{\circ} \mathrm{C}$. For cell culture, gentamycin and gelatin (type A, cell culture tested) were obtained from Wako and Sigma-Aldrich, respectively.

\section{Cell culture}

iCell cardiomyocytes were purchased from Cellular Dynamics International (Madison, WI, USA). The cells were seeded at a density of $5 \times 10^{5}$ cells/well onto 6 -well plates and maintained in the plating medium at $37^{\circ} \mathrm{C}$ in a humidified incubator with $7 \% \mathrm{CO}_{2}$, according to the manufacturer's protocol. The plating medium was replaced with the maintenance medium supplemented with gentamycin $(50 \mu \mathrm{g} / \mathrm{mL})$ at $48 \mathrm{hr}$ after seeding. The medium was then changed every other day until 6 days after seeding. For drug treatments, drugs were diluted with the maintenance medium and added to the cells by replacing the culture medium. The cells were cultured with the drugs for $24 \mathrm{hr}$. The vehicle solvent (DMSO/methanol) was used as a control in all experiments at a concentration of $0.1 \%$.

\section{Comprehensive gene expression analysis}

A comprehensive gene expression analysis was carried out according to previous reports (Miura et al., 2006; Okabe et al., 2015). Briefly, synthetic polynucleotides (80-mers) representing 14,400 human transcripts (MicroDiagnostic, Tokyo, Japan) were arrayed using a custom arrayer. Total RNA was extracted from hiPSCMs using ISOGEN (Nippon Gene, Tokyo, Japan). Total RNA (5 $\mu \mathrm{g})$ was labeled with SuperScript II (Invitrogen, Carlsbad, CA, USA) and cyanine 5-dUTP (PerkinElmer, Wellesley, MA, USA) for samples or cyanine 3-dUTP (PerkinElmer) for a human common reference RNA, which was prepared by mixing equal amounts of total RNA extracted from 22 cell lines. Hybridization was performed with a labeling and hybridization kit (MicroDiagnostic). Signals were measured with a GenePix 4000B scanner (Molecular Devices, Sunnyvale, CA, USA).

The signals were converted into primary expression ratios (the ratio of cyanine-5 intensity of each sample to cyanine- 3 intensity of the human common reference RNA). Each ratio was normalized by multiplication with normalization factors using Gene Pix Pro 3.0 software (Molecular Devices). The primary expression ratio was converted into $\log _{2}$ values (designated as $\log$ ratios). The mean average log ratio of the non-drug-treated cells was calculated for each transcript and was then subtracted from the log ratio for each transcript (designated as subtracted $\log$ ratios). The subtracted log ratios were used as the final data for analysis. Spots that exhibited fluorescence intensities below the detection limit were assigned a $\log$ ratio of 0 and were not included in the signal calculations of the averages and subtracted log ratios. The data were processed using Microsoft Excel software (Microsoft, Redmond, WA, USA) and the MDI gene expression analysis software package (MicroDiagnostic). Two-group comparisons between arrhythmogenic drugtreated and non-drug-treated cells were carried out using Welch's $t$-tests. Among the genes that showed significant differences $(P<1.0 \mathrm{E}-12)$ in their expression levels between arrhythmogenic drug-treated and non-drug-treated cells, we chose genes having mean average subtracted $\log$ ratios greater than 1 . 
Evaluation system for arrhythmogenic potential of drugs with hiPS-CMs

\section{RESULTS AND DISCUSSION}

To develop an evaluation system for the arrhythmogenic drug potential associated with QT prolongation, we selected 8 arrhythmogenic (Table 1) and 17 non-arrhythmogenic (Table 2) drugs among oral drugs, including circulatory system, allergy, and urogenital and anal organ drugs. The eight arrhythmogenic drugs, including five withdrawn drugs, have been reported to clinically induce TdP by QT prolongation (Japan Pharmaceutical
Reference; Fermini and Fossa, 2003).

We cultured iCell cardiomyocytes as hiPS-CMs and observed that the cells started their beating at $24 \mathrm{hr}$ after seeding. When the cells displayed spontaneous and stable beating for 6 days after seeding, they were treated with the drugs. In preliminary experiments, treatment of drugs for several hours did not induce gene expression changes in the cells. In addition, cell toxicity was apparent when hiPS-CMs were treated with the drugs for $>24 \mathrm{hr}$ at the concentrations described below (data not shown). For

Table 1. Arrhythmogenic drugs.

\begin{tabular}{|c|c|c|c|c|c|}
\hline Drug & Therapeutic category & $C_{\max }(\mu \mathrm{M})$ & $\begin{array}{l}\text { Concentration } \\
(\mu \mathrm{M})\end{array}$ & $\begin{array}{l}\text { Beating frequency } \\
\text { change }\end{array}$ & $\begin{array}{l}\text { Morphology } \\
\text { change }\end{array}$ \\
\hline Amiodarone & Antiarrhythmic agents & 0.10 & 10 & Arrest & No change \\
\hline Astemizole & Antiallergic agents & 4.40 & 10 & Arrest & Shrink \\
\hline Bepridil & Antiarrhythmic agents & 0.30 & 10 & Arrest & Shrink \\
\hline Cisapride & Psychotropics & 0.18 & 10 & Arrest & No change \\
\hline Mibefradil & Antihypertensives & 1.60 & 10 & Arrest & Shrink \\
\hline Propafenone & Antiarrhythmic agents & 0.16 & 10 & Arrest & Rounded \\
\hline Terfenadine & Antiallergic agents & 0.65 & 10 & Increase & Shrink \\
\hline Terodiline & Urogenital and anal organ agents & 0.94 & 100,10 & Arrest & Shrink \\
\hline
\end{tabular}

$C_{\max }$ is the maximum blood concentration, and the values are referenced in the Japan Pharmaceutical Reference, except astemizole (Bachmann et al., 1997), mibefradil (Wiltshire et al., 1997), and terodiline (Hartigan-Go et al., 1996). The concentration column shows treatment concentrations of the drugs. The beating frequency change column shows effects on the beating frequency of cardiomyocytes at $24 \mathrm{hr}$ of drug treatment. The morphology change column shows the effects of drugs on cell morphology at $24 \mathrm{hr}$ after treatment.

Table 2. Non-arrhythmogenic drugs.

\begin{tabular}{|c|c|c|c|c|c|}
\hline Drug & Therapeutic category & $C_{\max }(\mu \mathrm{M})$ & $\begin{array}{c}\text { Concentration } \\
(\mu \mathrm{M})\end{array}$ & $\begin{array}{l}\text { Beating frequency } \\
\text { change }\end{array}$ & $\begin{array}{l}\text { Morphology } \\
\text { change }\end{array}$ \\
\hline Aliskiren & Antihypertensives & 0.07 & 100,10 & $\begin{array}{c}\text { Arrest }(100 \mu \mathrm{M}), \\
\text { no change }(10 \mu \mathrm{M})\end{array}$ & No change \\
\hline Ambrisentan & Cardiovascular agents & 0.96 & 100 & No change & No change \\
\hline Amlodipine & Vasodilators & 0.004 & 10,1 & Arrest & Shrink \\
\hline Atorvastatin & Hyperlipidemia agents & 0.003 & 64 & No change & No change \\
\hline Bisoprolol & Antiarrhythmic agents & 0.02 & 100,10 & No change & No change \\
\hline Candesartan & Antihypertensives & 0.10 & 100 & No change & No change \\
\hline Clonidine & Antihypertensives & 0.005 & 100 & No change & No change \\
\hline Efonidipine & Antihypertensives & 0.021 & 50,10 & Arrest & Shrink \\
\hline Glyburide & Antidiabetic agents & 0.17 & 100 & Increase & No change \\
\hline Ketotifen & Antiallergic agents & 0.012 & 10 & No change & No change \\
\hline Linagliptin & Antidiabetic agents & 0.02 & 50,10 & Decrease & No change \\
\hline Lisinopril & Antihypertensives & 0.09 & 100 & No change & Shrink \\
\hline Naftopidil & Urogenital and anal organ agents & 0.01 & 10 & Increase & No change \\
\hline Nicorandil & Vasodilators & 0.72 & 100 & Increase & No change \\
\hline Prasugrel & Blood and body fluid agents & 0.43 & 100 & Increase & No change \\
\hline Sumatriptan & Vasoconstrictors & 0.08 & 50 & No change & No change \\
\hline Warfarin & Anticoagulants & 0.40 & 100 & No change & No change \\
\hline
\end{tabular}

$C_{\max }$ is the maximum blood concentration, and the values are referenced in the Japan Pharmaceutical Reference. The concentration column shows treatment concentrations of the drugs. The beating frequency change column shows effects on the beating frequency of cardiomyocytes at $24 \mathrm{hr}$ of drug treatment. The morphology change column shows the effects of drugs on cell morphology at $24 \mathrm{hr}$ after treatment. 
these reasons, we chose a time point of $24 \mathrm{hr}$ after drug treatment. First, the cells were treated with the drugs at a concentration of $100 \mu \mathrm{M}$. If the drugs induced cytotoxicity or were insoluble in the medium, they were used at a concentration of $10 \mu \mathrm{M}$, except atorvastatin, efonidipine, linagliptin, and sumatriptan, which were used at concentrations of 64 and $50 \mu \mathrm{M}$ (Tables 1 and 2). After $24 \mathrm{hr}$, the treated cells were observed under a microscope. Drug cytotoxicity was judged by the RNA yield from the cells and morphology compared with that of the vehicle controls. The arrhythmogenic drugs arrested the beating of the cells, except terfenadine, which increased the beating frequency (Table 1). Moreover, astemizole, bepridil, mibefradil, propafenone, terfenadine, and terodiline induced morphological changes in the cardiomyocytes (Table 1). Although aliskiren $(100 \mu \mathrm{M})$, amlodipine (1 and $10 \mu \mathrm{M})$, and efonidipine $(10$ and $50 \mu \mathrm{M})$ are nonarrhythmogenic drugs, they arrested the beating of the cells. Glyburide, naftopidil, nicorandil, and prasugrel caused an increase in the beating frequency, and linagliptin decreased the beating frequency (Table 2). In addition, the cells treated with amlodipine, efonidipine, and lisinopril displayed morphological changes (Table 2).

Next, we performed a comprehensive gene expression analysis to determine whether any genes were upregulated by the eight arrhythmogenic drugs in hiPS-CMs. Nineteen genes (Table 3) were upregulated in the arrhythmogenic drug-treated cells compared with their expression in the non-drug-treated cells, but were not upregulat- ed in the cells treated with the non-arrhythmogenic drugs. A heat map of the expression profiles of the 19 genes is shown in Fig. 1 (A). Terodiline altered gene expression in a concentration-dependent manner (Figs. 1 (A) and 2 ). The concentration dependence for the change in gene expression in hiPS-CMs treated with astemizole at concentrations of 10 and $1 \mu \mathrm{M}$ was also observed (data not shown).

The expression levels of the 19 genes were scored, and arrhythmogenic risks of the drugs were evaluated using the scores (Fig. 1 (B)). The scores showed high reproducibility in seven tests individually performed with astemizole (Fig. 1 (A)). A score of $>15$ indicated an arrhythmogenic risk (Fig. 1 (B)), because a score of 15 (i.e., from $10 \mu \mathrm{M}$ terodiline) could obviously distinguish the arrhythmogenic drugs from the highest score of the vehicle controls (Fig. 1 (B), red frame). As predicted, all arrhythmogenic drugs showed arrhythmogenic risks (Fig. 1 (B)). The scores of astemizole, bepridil, and terfenadine were above 35, showing that they exhibit high arrhythmia risks (Fig. 1 (B)). Recently, it was demonstrated that drugs could be categorized into three TdP risks based on the effect of the drugs on extracellular field potential with MEA (Ando et al., 2017). According to that report, astemizole and bepridil were classified as intermediate risk, which was slightly different from our study. This may have resulted from different concentrations or treatment periods of drugs between the studies. Furthermore, terfenadine was categorized as low risk (Ando et

Table 3. Upregulated genes identified by gene expression analysis.

\begin{tabular}{|c|c|c|}
\hline Gene symbol & Protein name & Accession No. \\
\hline CYP51A1 & Cytochrome P450, family 51, subfamily A, polypeptide 1 & NM_000786 \\
\hline DHCR7 & 7-Dehydrocholesterol reductase & NM_001360 \\
\hline FDPS & Farnesyl diphosphate synthase & NM_002004 \\
\hline \multirow[t]{2}{*}{$S Q L E$} & Squalene epoxidase & NM_003129 \\
\hline & Homo sapiens cDNA FLJ35015 fis, clone OCBBF2014229 & AK092334 \\
\hline$H M G C R$ & 3-Hydroxy-3-methylglutaryl-CoA reductase & NM_000859 \\
\hline LPIN1 & Lipin 1 & NM_145693 \\
\hline FDFT1 & Farnesyl-diphosphate farnesyltransferase 1 & NM_004462 \\
\hline FASN & Fatty acid synthase & NM_004104 \\
\hline TMEM97 & Transmembrane protein 97 & NM_014573 \\
\hline$H S D 17 B 7$ & Hydroxysteroid (17-beta) dehydrogenase 7 & NM_-016371 \\
\hline STARD4 & StAR-related lipid transfer (START) domain containing 4 & NM_139164 \\
\hline$H M G C S 1$ & 3-Hydroxy-3-methylglutaryl-CoA synthase 1 (soluble) & NM_002130 \\
\hline MSMO1 & Methylsterol monooxygenase 1 & NM_006745 \\
\hline$I D I 1$ & Isopentenyl-diphosphate delta isomerase 1 & NM_-004508 \\
\hline$A C A T 2$ & Acetyl-CoA acetyltransferase 2 & NM_005891 \\
\hline DHCR 24 & 24-Dehydrocholesterol reductase & NM_014762 \\
\hline INSIG1 & Insulin-induced gene 1 protein & NM_005542 \\
\hline$S C D$ & Stearoyl-CoA desaturase (delta-9-desaturase) & NM_005063 \\
\hline
\end{tabular}


Evaluation system for arrhythmogenic potential of drugs with hiPS-CMs

(A) Drugs warrhythmogenic drug (withdrawal) =arrhythmogenic drug "non-arrhythmogenic drug "vehicle Concentrations $=1 \mu \mathrm{M}=10 \mu \mathrm{M}=50 \mu \mathrm{M}=64 \mu \mathrm{M}=100 \mu \mathrm{M}$

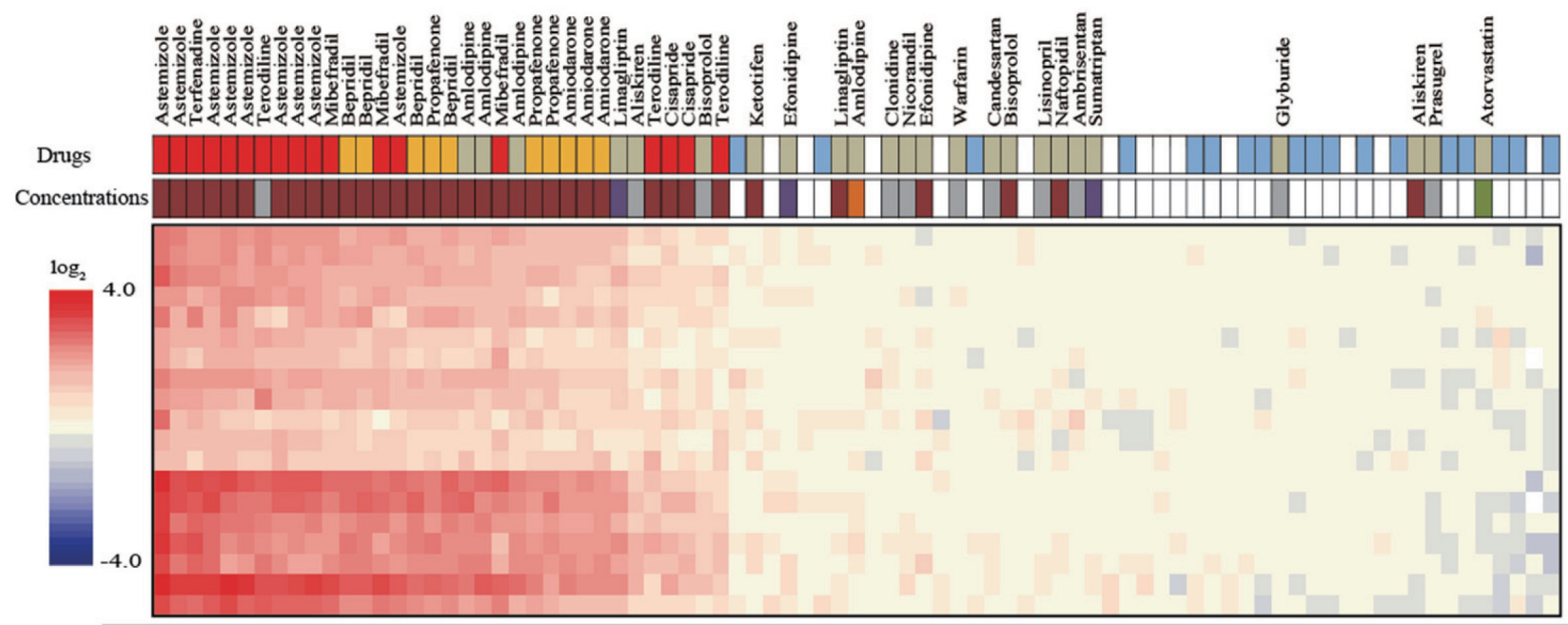

(B)

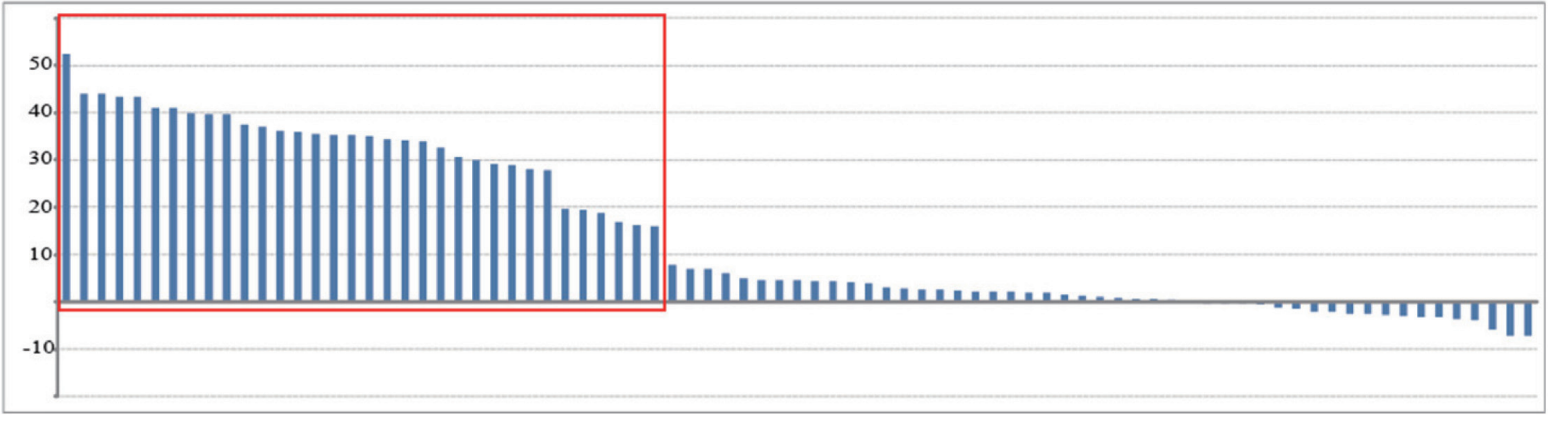

Fig. 1. Evaluation of arrhythmogenic risks by scoring gene expression levels. (A) Heat map of 19 genes upregulated in arrhythmogenic drug-treated cells. Expression values (subtracted log ratios) are presented in color. Red and blue colors indicate high and low expression, respectively. White indicates a log ratio of 0 . The color box under each drug's name indicates the type of drug: red is an arrhythmogenic drug that was withdrawn from the market; orange is an arrhythmogenic drug; tan is a non-arrhythmogenic drug; light blue is vehicle; white is no treatment. The color boxes directly above the heat map show the concentration of drugs: gray, $100 \mu \mathrm{M}$; green, $64 \mu \mathrm{M}$; violet, $50 \mu \mathrm{M}$; deep red, $10 \mu \mathrm{M}$; deep orange, $1 \mu \mathrm{M}$. (B) Scoring of gene expression levels of the 19 genes. The graph shows the sum of the expression values (subtracted log ratios) of the 19 genes for each sample. The scores classified as arrhythmogenic risks are shown in the red square.

al., 2017), although this drug was withdrawn from the market. These results indicate that our evaluation system for arrhythmia by gene expression analysis is highly accurate for some drugs.

In the score analysis, almost all non-arrhythmogenic drugs showed no risk, except aliskiren, amlodipine, bisoprolol, and linagliptin (Fig. 1 (B)). However, the results of the arrhythmogenic risk evaluation and those of the beating frequency change induced by the drugs were not identical. Thus, we considered the relationship between the risk and maximum blood concentration $\left(C_{\max }\right)$ of the drugs. The treatment concentrations of the arrhythmogenic drugs were less than or equal to 100 times of their $C_{\max }$ values (Fig. 2). However, the treatment concentrations of aliskiren $(100 \mu \mathrm{M})$, amlodipine $(10 \mu \mathrm{M})$, bisoprolol $(100 \mu \mathrm{M})$, and linagliptin $(50 \mu \mathrm{M})$ far exceeded their 100fold $C_{\max }$ values. Therefore, these compounds were retested at a concentration of 1 or $10 \mu \mathrm{M}$, which was slightly above 100 times their $C_{\max }$ values (Table 2). Consequently, these compounds did not show arrhythmogenic risks (Fig. 2). Overall, these results indicate that when a drug exhibits an arrhythmogenic risk in our cell-based evaluation system at a concentration 100 times higher than its $C_{\max }$ value, the drug may induce arrhythmia upon oral administration in the clinic.

Of the 19 upregulated genes, 11 genes (DHCR7, FDPS, 
A. Higa et al.

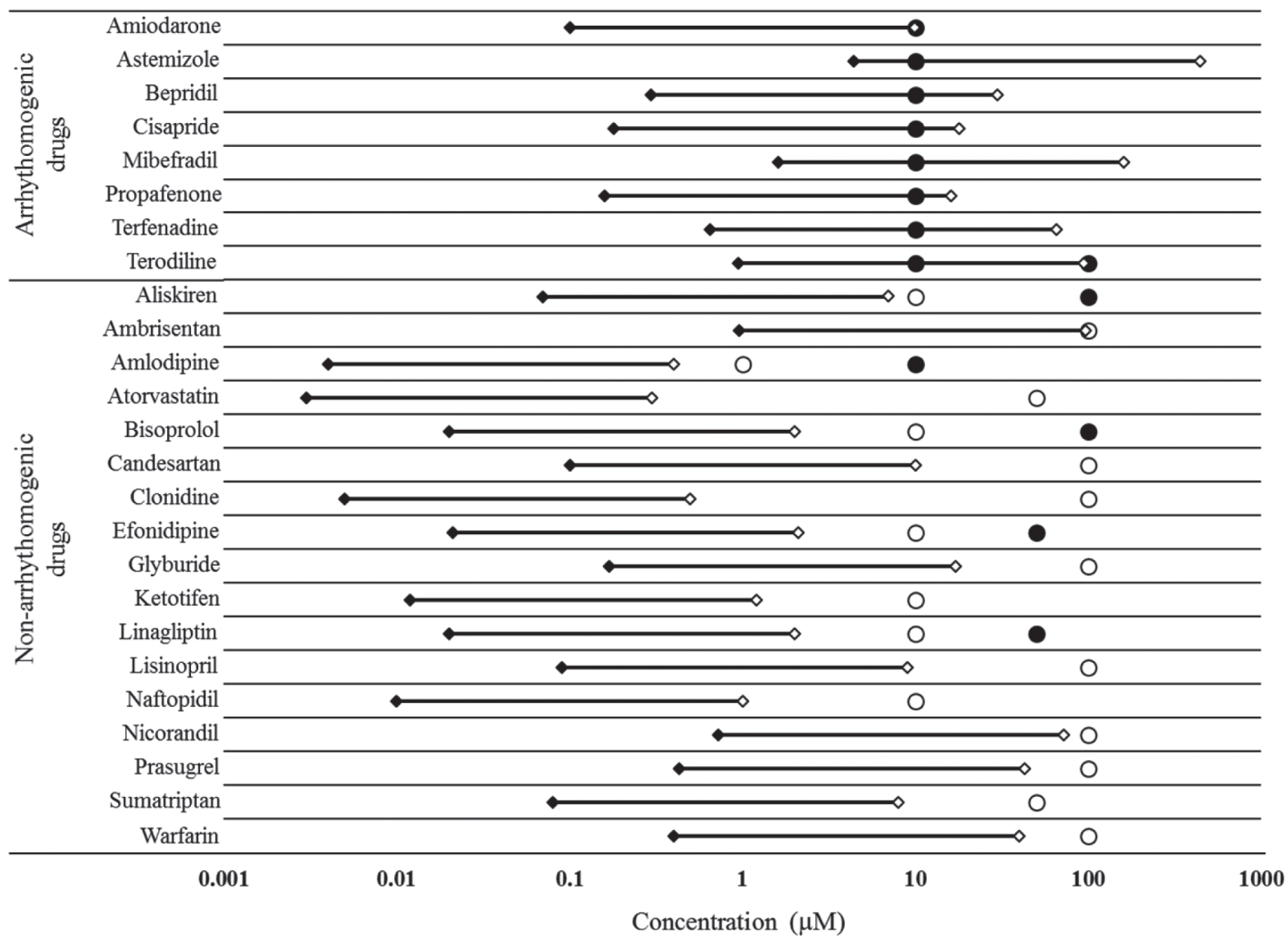

Fig. 2. Relationships between arrhythmogenic risks and maximum blood concentrations of drugs. The arrhythmogenic risks of the drugs are shown at each treatment concentration: open circles, no risk; filled circles, arrhythmogenic risk. Black and white diamonds with lines drawn between them indicate $C_{\max }$ and the concentration of 100 times of $C_{\max }$, respectively.

SQLE, HMGCR, FDFT1, HSD17B7, HMGCS1, MSMO1, $I D H, A C A T 2$, and DHCR24) were cholesterol biosynthetic genes (Table 3). Their encoded enzymes, involved in cholesterol biosynthesis, impact cell membrane fluidity, and an increase in cholesterol upon activation of these enzymes lowers membrane fluidity. These results suggest that long-term exposure to arrhythmogenic drugs induces changes in membrane fluidity in cardiomyocytes.

In conclusion, we succeeded in evaluating the arrhythmogenic potential of drugs, associated with QT prolongation, by scoring the expression levels of 19 genes in drug-treated cardiomyocytes. This evaluation system will be a useful new tool capable of accurately predicting the arrhythmogenic potential for preclinical cardiac safety assessment of drugs.

\section{ACKNOWLEDGMENTS}

This research was supported by grants for translational research programs from Fukushima Prefecture.

Conflict of interest---- The authors declare that there is no conflict of interest.

\section{REFERENCES}

Ando, H., Yoshinaga, T., Yamamoto, W., Asakura, K., Uda, T., Taniguchi, T., Ojima, A., Shinkyo, R., Kikuchi, K., Osada, T., Hayashi, S., Kasai, C., Miyamoto, N., Tashibu, H., Yamazaki, D., Sugiyama, A., Kanda, Y., Sawada, K. and Sekino, Y. (2017): A new paradigm for drug-induced torsadogenic risk assessment using human iPS cell-derived cardiomyocytes. J. Pharmacol. Toxicol. Methods, 84, 111-127.

Asakura, K., Hayashi, S., Ojima, A., Taniguchi, T., Miyamoto, 
Evaluation system for arrhythmogenic potential of drugs with hiPS-CMs

N., Nakamori, C., Nagasawa, C., Kitamura, T., Osada, T., Honda, Y., Kasai, C., Ando, H., Kanda, Y., Sekino. Y. and Sawada, K. (2015): Improvement of acquisition and analysis methods in multi-electrode array experiments with iPS cellderived cardiomyocytes. J. Pharmacol. Toxicol. Methods, 75, 17-26.

Bachmann, K., Sullivan, T.J., Reese, J.H., Jauregui, L., Miller, K., Scott, M., Stotka, J. and Harris, J. (1997): A study of the interaction between dirithromycin and astemizole in healthy adults. Am. J. Ther., 4, 73-79.

Dick, E., Rajamohan, D., Ronksley, J. and Denning, C. (2010): Evaluating the utility of cardiomyocytes from human pluripotent stem cells for drug screening. Biochem. Soc. Trans., 38, 10371045.

Fermini, B. and Fossa, A.A. (2003): The impact of drug-induced QT interval prolongation on drug discovery and development. Nat. Rev. Drug Discov., 2, 439-447.

Guo, L., Abrams, R.M., Babiarz, J.E., Cohen, J.D., Kameoka, S., Sanders, M.J., Chiao, E. and Kolaja, K.L. (2011): Estimating the risk of drug-induced proarrhythmia using human induced pluripotent stem cell-derived cardiomyocytes. Toxicol. Sci., 123, 281-289.

Guo, L., Coyle, L., Abrams, R.M., Kemper, R., Chiao, E.T. and Kolaja, K.L. (2013): Refining the human iPSC-cardiomyocyte arrhythmic risk assessment model. Toxicol. Sci., 136, 581-594.

Hartigan-Go, K., Bateman, D.N., Daly, A.K. and Thomas, S.H. (1996): Stereoselective cardiotoxic effects of terodiline. Clin. Pharmacol. Ther., 60, 89-98.

Hayakawa, T., Kunihiro, T., Ando, T., Kobayashi, S., Matsui, E., Yada, H., Kanda, Y., Kurokawa, J. and Furukawa, T. (2014): Image-based evaluation of contraction-relaxation kinetics of human-induced pluripotent stem cell-derived cardiomyocytes: correlation and complementarity with extracellular electrophysiology. J. Mol. Cell Cardiol., 77, 178-191.

Higa, A., Hoshi, H. and Takagi, M. (2016): Differing responses of human stem cell-derived cardiomyocytes to arrhythmogenic drugs, determined using impedance measurements. Fundam. Toxicol. Sci., 3, 47-53

Himmel, H.M. (2013): Drug-induced functional cardiotoxicity screening in stem cell-derived human and mouse cardiomyocytes: effects of reference compounds. J. Pharmacol. Toxicol. Methods, 68, 97-111.

Honda, M., Kiyokawa, J., Tabo, M. and Inoue, T. (2011): Electrophysiological characterization of cardiomyocytes derived from human induced pluripotent stem cells. J. Pharmacol. Sci., 117, 149-159.

Lopez-Izquierdo, A., Warren, M., Riedel, M., Cho, S., Lai, S., Lux, R.L., Spitzer, K.W., Benjamin, I.J., Tristani-Firouzi, M. and Jou, C.J. (2014): A near-infrared fluorescent voltage-sensitive dye allows for moderate-throughput electrophysiological analyses of human induced pluripotent stem cell-derived cardiomyocytes. Am. J. Physiol. Heart Circ. Physiol., 307, H1370-H1377.

Miura, A., Honma, R., Togashi, T., Yanagisawa, Y., Ito, E., Imai, J., Isogai, T., Goshima, N., Watanabe, S. and Nomura, N. (2006):
Differential responses of normal human coronary artery endothelial cells against multiple cytokines comparatively assessed by gene expression profiles. FEBS Lett., 580, 6871-6879.

Nguemo, F., Šarić, T., Pfannkuche, K., Watzele, M., Reppel, M. and Hescheler, J. (2012): In vitro model for assessing arrhythmogenic properties of drugs based on high-resolution impedance measurements. Cell Physiol. Biochem., 29, 819-832.

Nozaki, Y., Honda, Y., Watanabe, H., Saiki, S., Koyabu, K., Itoh, T., Nagasawa, C., Nakamori, C., Nakayama, C., Iwasaki, H., Suzuki, S., Tanaka, K., Takahashi, E., Miyamoto, K., Morimura, K., Yamanishi, A., Endo, H., Shinozaki, J., Nogawa, H., Shinozawa, T., Saito, F. and Kunimatsu, T. (2017): CSAHi study-2: Validation of multi-electrode array systems (MEA60/2100) for prediction of drug-induced proarrhythmia using human iPS cell-derived cardiomyocytes: Assessment of reference compounds and comparison with non-clinical studies and clinical information. Regul. Toxicol. Pharmacol., 88, 238251.

Nozaki, Y., Honda, Y., Watanabe, H., Saiki, S., Koyabu, K., Itoh, T., Nagasawa, C., Nakamori, C., Nakayama, C., Iwasaki, H., Suzuki, S., Washio, I., Takahashi, E., Miyamoto, K., Yamanishi, A., Endo, H., Shinozaki, J., Nogawa, H. and Kunimatsu, T. (2016): CSAHi study: Validation of multi-electrode array systems (MEA60/2100) for prediction of drug-induced proarrhythmia using human iPS cell-derived cardiomyocytes -assessment of inter-facility and cells lot-to-lot-variability. Regul. Toxicol. Pharmacol., 77, 75-86.

Okabe, N., Ezaki, J., Yamaura, T., Muto, S., Osugi, J., Tamura, H., Imai, J., Ito, E., Yanagisawa, Y., Honma, R., Gotoh, M., Watanabe, S., Waguri, S. and Suzuki, H. (2015): FAM83B is a novel biomarker for diagnosis and prognosis of lung squamous cell carcinoma. Int. J. Oncol., 46, 999-1006.

Omata, T., Kasai, C., Hashimoto, M., Hombo, T. and Yamamoto, K. (2005): QT PRODACT: comparison of non-clinical studies for drug-induced delay in ventricular repolarization and their role in safety evaluation in humans. J. Pharmacol. Sci., 99, 531-541.

Šarić, T., Halbach, M., Khalil, M. and Er, F. (2014): Induced pluripotent stem cells as cardiac arrhythmic in vitro models and the impact for drug discovery. Expert Opin. Drug Discov., 9, 55-76.

Wiltshire, H.R., Sutton, B.M., Heeps, G., Betty, A.M., Angus, D.W., Harris, S.R., Worth, E. and Welker, H.A. (1997): Metabolism of the calcium antagonist, mibefradil (POSICOR, Ro 40-5967). Part III. Comparative pharmacokinetics of mibefradil and its major metabolites in rat, marmoset, cynomolgus monkey and man. Xenobiotica, 27, 557-571.

Yamamoto, W., Asakura, K., Ando, H., Taniguchi, T., Ojima, A., Uda, T., Osada, T., Hayashi, S., Kasai, C., Miyamoto, N., Tashibu, H., Yoshinaga, T., Yamazaki, D., Sugiyama, A., Kanda, Y., Sawada, K. and Sekino, Y. (2016): Electrophysiological characteristics of human iPSC-derived cardiomyocytes for the assessment of drug-induced proarrhythmic potential. PLoS One, 11, e0167348. 